\title{
Article \\ Overexpression of GhKTI12 Enhances Seed Yield and Biomass Production in Nicotiana Tabacum
}

\author{
Aye Aye Myat ${ }^{1,+}{ }^{+}$Yu Zhou ${ }^{1,+}$, Yuan Gao ${ }^{1,+}$, Xiang Zhao ${ }^{1}$, Chengzhen Liang ${ }^{1}$, Muhammad Ali Abid ${ }^{1}$, \\ Peilin Wang ${ }^{1}\left(\mathbb{D}\right.$, Umar Akram ${ }^{1,2}{ }^{\mathbb{D}}$, Mubashir Abbas ${ }^{1}$, Muhammad Askari ${ }^{1}$, Sandui Guo ${ }^{1}$, Rui Zhang ${ }^{1} \mathbb{D}$ \\ and Zhigang Meng ${ }^{1, * \mathbb{D}}$
}

\section{check for} updates

Citation: Myat, A.A.; Zhou, Y.; Gao, Y.; Zhao, X.; Liang, C.; Abid, M.A.; Wang, P.; Akram, U.; Abbas, M.; Askari, M.; et al. Overexpression of GhKTI12 Enhances Seed Yield and Biomass Production in Nicotiana Tabacum. Genes 2022, 13, 426. https://doi.org/10.3390/ genes13030426

Academic Editors: Mingli Wang and Paola Vittorioso

Received: 9 February 2022 Accepted: 23 February 2022 Published: 25 February 2022

Publisher's Note: MDPI stays neutral with regard to jurisdictional claims in published maps and institutional affiliations.

Copyright: (C) 2022 by the authors. Licensee MDPI, Basel, Switzerland. This article is an open access article distributed under the terms and conditions of the Creative Commons Attribution (CC BY) license (https:// creativecommons.org/licenses/by/ $4.0 /)$.
1 Biotechnology Research Institute, Chinese Academy of Agricultural Sciences, Beijing 100081, China; aamyat19may@gmail.com (A.A.M.); 82101182062@caas.cn (Y.Z.); plateau1995@163.com (Y.G.); zx19921301161@163.com (X.Z.); liangchengzhen@caas.cn (C.L.); abid@caas.cn (M.A.A.); wangpeilin19@126.com (P.W.); umar02kw1@gmail.com (U.A.); mubashirabbas3164@yahoo.com (M.A.); askaricaas5@yahoo.com (M.A.); guosandui@caas.cn (S.G.); zhangrui@caas.cn (R.Z.)

2 Institute of Plant Breeding and Biotechnology, MNS-University of Agriculture, Multan 60000, Pakistan

* Correspondence: mengzhigang@caas.cn

+ These authors contributed equally to this work.

\begin{abstract}
Crop molecular breeding primarily focuses on increasing the trait of plant yield. An elongator-associated protein, KTI12, is closely associated with plant biomass and yield. KTI12 is involved in developmental processes of most organs, including the leaf, root, flower, and seed, through regulating cell division and differentiation. Previous work has shown that in upland cotton (Gossypium hirsutum), GhKTI12 regulates plant height, flowering, and tolerance to salt and drought stress. However, little is known about the molecular regulation mechanism of GhKTI12 in plant developmental processes. In this study, we identified the main GhKTI12 (Gh_D02G144400) gene and transformed it into tobacco (Nicotonia tabacum cv NC89). From seven transgenic lines, we obtained three (OE5, OE6 and OE8) with high expression of GhKTI12; compared with wild type plants, these three lines exhibited larger plant size, later flowering, and higher seed yield. Microscopic observation revealed that the number of leaf epidermal cells and stem parenchyma cells was increased by $\sim 55 \%$. Biochemical analysis showed that chlorophyll content and starch accumulation were significantly increased in younger leaves at the top canopy of transgenic plants, which may contribute to improved photosynthetic rate and, in turn, increased seed yield. To understand the molecular mechanism of GhKTI12 in transgenic plants development, two lines (OE6 and OE8) with higher expression levels of GhKTI12 were used as representative plants to conduct RNA-seq analysis. Through transcriptome analysis of the plant's shoot apical meristematic tissue of these two lines, we identified 518 upregulated genes and 406 downregulated genes common to both overexpression lines. A large number of cellular component genes associated with cell division and differentiation, such as RD21, TET8, KTN80, AOX1, AOX2, CP1, and KIC, were found to be upregulated, and genes showing the most downregulation included MADS-box genes related to flowering time, such as MADS6, AP1, AP3, AGL8, AGL6, SEP1, and SEP2. Downregulation of these genes caused delayed flowering time and longer vegetative stage during development. Combined with the upregulation of the yield-related gene RD21, the GhKTI12 transgenic plants could produce a higher seed yield. We here show that the overexpression of GhKTI12 could positively improve key agronomic traits in tobacco by regulating cell proliferation, photosynthesis, and organ development, and suggest that homologs of GhKTI12 may also be important in the genetic improvement of other crop plants.
\end{abstract}

Keywords: GhKTI12; seed yield; biomass; transgenic tobacco

\section{Introduction}

The KTI (Killer Toxin Insensitive or Kluyveromyces lactis Toxin Insensitive) gene encodes an elongator-associated protein. Three KTI genes (KTI11, KTI12, and KTI13) 
were initially isolated from Saccharomyces cerevisiae [1-4]. KTI12 is a highly conserved ATPase, and is necessary for the tRNA-modification activity of the eukaryotic Elongator complex [3,5]. KTI12 homologs have been identified in many plants, such as Arabidopsis thaliana, Oryza sativa, Zea mays, Brassica napus, Populus [6].

Yeast KTI12 and plant orthologs contain an N-terminal P-loop motif [7] and a putative calmodulin binding domain (CBD) [8]. Loss of CBD on the C-terminal of KTI12 results in zymocin resistance in yeast $[9,10]$. The P-loop motif is the primary functional area of the KTI12 protein and contains O-phospho-seryl-tRNA-kinase (PSTK) activity. It is conserved in all known KTI12 homologs and is an essential component for elongator-dependent tRNA modification [9]. Like the CBD terminal, loss of the P-loop function in KTI12 yeast mutants results in zymocin resistance [11]. In plants, the P-loop region in KTI12 regulates leaf morphogenesis via wobble uridine modification [6]. A recent study revealed that deficiencies in tRNA wobble modification alter leaf development through increasing leaf epidermal cells in the Atelp3 mutant [12].

Plant KTI12 homologs are localized to the nucleus [3] and regulate gene transcription through interaction with elongator, a complex containing two sub-complexes and six subunits (ELP1-ELP6) that are highly conserved in eukaryotic organisms including yeast, humans, and Arabidopsis [13]. The core subcomplex of an elongator consists of ELP1, ELP2 and ELP3. KTI12 can affect tRNA modification to regulate plant development through interaction with ELP. Mutation of AtKTI12 and AtELP1 in Arabidopsis were shown to reduce organ growth and early flowering, respectively [14].

DEFORMED ROOTS AND LEAVES1 (DRL1) is a KTI12 homolog that can modulate cell division and differentiation to regulate meristem activity and organ growth in Arabidopsis [4,8]. AtDRL1/KTI12 mutants in Arabidopsis have defective shoot and root meristems $[4,15]$. Complementation experiments of yeast KTI12 with Arabidopsis and rice drl1 mutant showed rescued growth retardation [8].However, ELP mutants in Arabidopsis show pleiotropic phenotypes including narrow leaves, enlargement of hypocotyl, retarded primary root growth, decreased seed germination, delayed flowering time, and reduced apical dominance $[4,9,16,17]$. The comprehensive morphological and molecular characterization of DRL1 and elongator gene mutants demonstrate that KTI12 and DRL1 have protein-protein interactions with the elongator in yeast and Arabidopsis, respectively.

Tobacco (Nicotiana tabacum L.) is an economically important plant, and the variety NC89 has been widely used as a model for gene functional analysis. In a previous study, we screened functional genes related to plant architecture, abiotic stress tolerance, and yield in cotton using RNA-seq data and the virus-induced gene silencing (VIGS) method. We found that KTI12 affects plant height, flowering, and tolerance to salt and drought stress in upland cotton. There are two homologous genes, Gh_A03G123100 and Gh_D02G144400, in the cotton genome. From gene expression profiles and stress-induced characteristics, we found that Gh_D02G144400 is likely the gene primarily responsible for KTI12 function. However, very few studies have functionally characterized the GhKTI12 gene. In this study, we transformed GhKTI12 (Gh_D02G144400) into the tobacco variety NC89. Transgenic tobacco plants with high expression of GhKTI12 were identified and used to analyze gene function based on phenotypes. The results of this study provide a better understanding of KTI12 gene function in key plant traits and lay an experimental foundation for genetic crop improvement.

\section{Materials and Methods}

\subsection{Plant Materials and Growth Conditions}

Tobacco seeds were provided by Biotechnology Research Institute, Chinese Academy of Agricultural Sciences Beijing, China. Seeds were germinated and grown in $\frac{1}{2}$ Murashige and Skoog (MS) medium Petri plates and incubated at $25^{\circ} \mathrm{C}$ in a growth chamber with a $16 \mathrm{~h}$ photoperiod for 15 days. Precultured leaves were used as explants for Agrobacterium tumefaciens-mediated genetic transformation [18]. 


\subsection{Plant Transformation and Identification of Transgenic Tobacco}

The overexpression vector pCAMBIA2300-35S-GhKTI12 was constructed by inserting the coding sequence of GhKTI12 into the empty vector pCAMBIA2300-35S between KpnI and SmaI sites. The pCAMBIA2300-35S plasmid was provided by Biotechnology Research Institute, Chinese Academy of Agricultural Sciences in Beijing, China. The overexpression vector was transformed into Agrobacterium strain GV3101. Transgenic tobacco plants were created by the Agrobacterium-mediated leaf disc method [19]. After obtaining kanamycinresistant plants, DNA was extracted from the transgenic and wild type (WT) plants by using NuClean Plant Genome DNA Kit (ComWin Biotech Co., Ltd., Jiangsu, China) to identify the target gene via PCR amplification. The PCR Mix was $2 \times$ Phanta Max Super-Fidelity DNA Polymerase (Vazyme Biotech Co., Ltd., Nanjing, China). Primers shown in Table S1 were used to amplify a 912-bp fragment of the GhKTI12 gene. The PCR program was as follows: pre-denaturation at $95^{\circ} \mathrm{C}$ for $3 \mathrm{~min} ; 30$ cycles of amplification $\left(95^{\circ} \mathrm{C}\right.$ for $30 \mathrm{~s}, 56^{\circ} \mathrm{C}$ for $45 \mathrm{~s}, 72{ }^{\circ} \mathrm{C}$ for $45 \mathrm{~s}$ ); followed by $5 \mathrm{~min}$ at $72{ }^{\circ} \mathrm{C}$. T2 homozygous lines were generated to conduct further experiments.

\subsection{Total RNA Isolation and $q R T-P C R$ Analysis}

For transcript expression analysis, RNA from different tissue samples was extracted using a FastPure Plant Total RNA Isolation Kit (Vazyme Biotech Co., Ltd., Nanjing, China). First-strand cDNA synthesis was conducted with HiScript II Q RT SuperMix for qPCR (+gDNA wiper) kit (Vazyme Biotech Co., Ltd., Nanjing, China), following the manufacturer's instructions. The $2^{-\Delta \Delta C T}$ method was used to calculate relative expression level [20], and NtACT7 was used as the internal reference gene. Primers are shown in Table S1. All qRT-PCR experiments were conducted with three technical replicates.

\subsection{Collection of Morphological Data of T2 Transgenic Tobacco}

Morphological traits of transgenic and WT plants were recorded for the T2 generation including leaf size, plant height, number of leaves, number of internodes, flowering time, capsule number, and seed yield at flowering time. The fresh and dry weight of vegetative tissues (leaves, stems, and roots) were measured. Transgenic plants were separately harvested and dried at $70{ }^{\circ} \mathrm{C}$ after harvesting.

\subsection{Chlorophyll Content Determination}

Chlorophyll content in transgenic and WT plants was determined as described by Parry (2014) [21]. Briefly, $0.1 \mathrm{~g}$ of plant tissue was homogenized in $80 \%$ acetone and incubated in the dark for $6 \mathrm{~h}$. The homogenate was centrifuged at $10,000 \times g$ for $10 \mathrm{~min}$. Absorbance of the supernatant was measured at 649 and $665 \mathrm{~nm}$ with a Spark plate reader (Tecan, Männedorf, Switzerland).

\subsection{Histological Analysis}

Leaf tissue and stem internode samples were collected from 45- to 60-day-old GhKTI12 transgenic and WT plants, then fixed in a solution of 3:1 ethanol: acetic anhydride with a drop of Tween-20 for $1 \mathrm{~h}$ [22]. Samples were dehydrated in a series of ethanol solutions (70\%, 80\%, 85\%, 90\%, 95\%, and 100\% anhydrous ethanol) and destained in a series of Technovit 7100 (Heraeus, Hanau, Germany) solutions (3:1 ethanol:xylene, 1:1 ethanol:xylene, 1:3 ethanol:xylene, and pure xylene). Each leaf sample was placed in a mold or microcentrifuge tube and Technovit solution. The resin polymerized overnight at $37^{\circ} \mathrm{C}$ in a closed environment. Tissue sections were cut with a glass knife, fixed on a glass slide, and stained with $0.05 \%$ Toluidine Blue O (Sigma-Aldrich Pty Ltd., Darmstadt, Germany). Microscopic observation of palisade cells and culm parenchyma cells was conducted using a digitized camera with differential interference contrast optics on Laser Confocal Zeiss LSM700 (Carl Zeiss Ltd., Oberkochen, Germany). 


\subsection{Determination of Sucrose and Starch Content}

For sucrose and starch content analysis, leaves were harvested from different positions (5th, 6th, 7th, 8th, 9th, and 10th) of three plants for the WT and each of the GhKTI12 overexpressing lines at the juvenile vegetative stage (approximately 60 days after sowing). A total of 18 leaf samples of three individual plant were selected from each transgenic line. Starch and sucrose content were measured using the $\beta$-Amylase Assay Kit and Sucrose Assay Kit (Beijing Solarbio Science \& Technology Co., Ltd. Beijing, China) according to the manufacturer protocols.

\subsection{RNA-Seq and Data Analysis}

Total RNA was extracted from the shoot apical meristem of 40-day-old plants with three samples for each line (OE-6, OE-8, and WT) using the RNeasy Plant Mini Kit (Qiagen $\mathrm{GmbH}$, Hilden, Germany). Libraries for RNA-seq analysis were constructed from $3 \mathrm{mg}$ of total RNA per sample using the RNA Library Prep Kit for Illumina (New England Biolabs, Ipswich, MA, USA). Constructed libraries used Illumina high throughput sequencing platform NovaSeq 6000 for sequencing. Differentially expressed genes (DEGs) were identified and gene ontology (GO) enrichment analysis was performed using TBtools [23] and agriGO v2.0 [24]. DEGs with adjusted $p$-value $<0.05$ were considered significant. The expression profile of DEGs were visualized with HemI (Heatmap Illustrator, v1.0) [25].

\subsection{Statistical Analysis for Physiological and Biochemical Experiment}

Data were analyzed using SPSS 20.0. Means were compared within transgenic and WT groups using Tukey's test at the 5\% and 1\% level. All of the morphological data for T2 transgenic progeny are presented as the mean \pm standard error and $p$-value. Differences between transgenic lines and WT were considered if $p<0.05$. Significantly, differences between transgenic lines and WT were considered if $p<0.01$.

\section{Results}

\subsection{Molecular Character of GhKTI12 and Identification of Transgenic Tobacco}

There are two GhKTI12 homologs in upland cotton, and Gh_D02G144400 is the main functional gene. The full-length coding sequence of GhKTI12 (Gh_D02G144400) is $912 \mathrm{bp}$ and encodes a protein of 303 amino acids in length with a molecular weight of $34 \mathrm{kDa}$ and an isoelectric point of 8.9 (Figure S1a). Hydropathy analysis showed that GhKTI12 contains no transmembrane domain, indicating that it is not a transmembrane protein (Figure S1b). Subcellular localization analysis revealed that GhKTI12 is localized to the nucleus (Figure S1c). The predicted secondary structure includes $\alpha$-helix $\mathrm{H}$ bond residues, extra coils, and turn coils (Figure S1d).

To elucidate the phylogenetic relationship of KTI12 orthologs among plants, a neighborjoining tree was constructed using KTI12 amino acid sequences from 16 plant species: Arabidopsis (Arabidopsis thaliana), rice ( Oryza sativa subsp. japonica and indica), maize (Zea mays), upland cotton, diploid cotton (Gossypium raimondii), island cotton (Gossypium barbadense), Gossypium arboretum, tobacco, arabica (Coffea arabica), white poplar (Populus tomentosa and Populus alba), Leprosy tree (Jatropha curcas), sesame (Sesamum indicum), potato (Solanum tuberosum), and rape (Brassica campestris) (Figure 1a). The phylogenetic tree showed that the GhKTI12 protein was more closely related to dicot species than monocot species, but there was a distant relationship between cotton GhKTI12 with some monocot species such as rice and maize. 
(a)

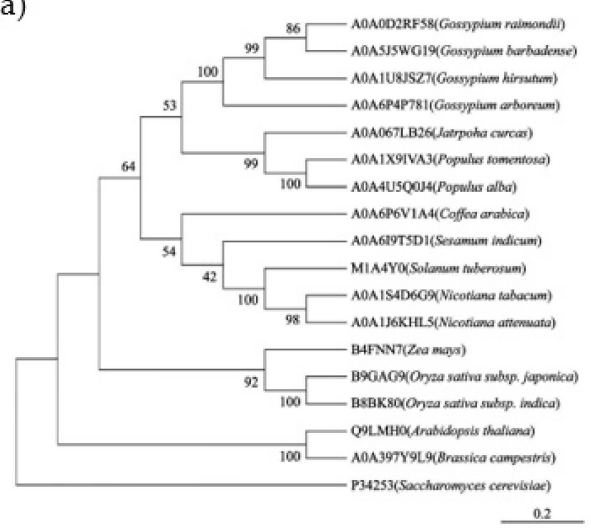

(b)

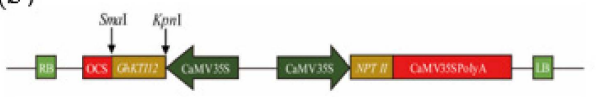

(c)

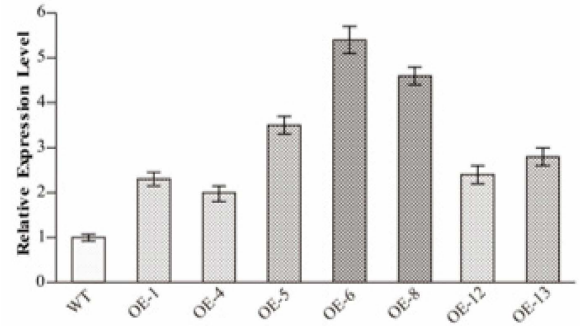

Figure 1. Phylogenetic analysis of GhKTI12 homologs and identification of transgenic plants. (a) Phylogenetic analysis of GhKTI12 homologs in plants. NJ tree is generated by MEGA-X software using full protein sequences. Numbers in each branch indicate distance genetic variation between species. GhKTI12 was shown as A0A1U8JSZ7 (upland cotton). (b) Vector constructions of GhKTI12 based on PCAMBIA2300-35S backbone. (c) qRT-PCR analysis of relative transcript level of GhKTI12 in T0 transgenic tobacco lines (Line 1-7). Bars in the graph show the standard mean error. Asterisks indicates significant differences between wild type (WT) and GhKTI12 transgenic plants analyzed by Student's $t$-test, $p<0.01$.

After transformation of the GhKTI12 overexpression vector (Figure 1b) into tobacco variety NC89, seven independent lines were obtained with kanamycin resistance selection and PCR identification (Figure S2a). The overexpression lines were named OE-1, OE-4, OE-5, OE-6, OE-8, OE-12, and OE-13. GhKTI12 expression was verified in all transgenic lines via qRT-PCR (Figure 1c). GhKTI12 expression was significantly higher in OE-5, OE-6 and OE-8 than in the other lines, and these were, therefore, selected for further study (Figure S2b).

\subsection{Overexpression of GhKTI12 Could Delay Flowering Time and Increase Plant Height}

To identify morphological characteristics, we generated T2 generation plants of OE-5, OE-6 and OE-8. The T2 plants were used to evaluate the number of leaves, internode number, flowering date, and plant height in the whole growth stage. While there was no significant difference in morphology between WT and OE lines before the flowering stage in 60-day-old seedlings (Figure S3a-c), the OE plants had a later flowering date, higher number of leaves, higher mainstem, and more internodes than WT plants (Figure 2a-c).

The initial flowering time was 115 days after sowing in the WT, whereas OE-5, OE-6 and OE-8 did not flower until 145 days, 142 days and 143 days after sowing, respectively (Figure 2d). In the flowering stage, the number of plant leaves in OE-6 and OE-8 were significantly increased compared to the WT (Figure S3d); WT plants had only $23.7 \pm 2$ leaves, but OE-5, OE-6 and OE-8 had $32.44 \pm 2,30.55 \pm 2$ and $30.75 \pm 5$ leaves, respectively. In addition to increased leaf number in transgenic plants, the plant height significantly increased and more internodes were developed in the stem (Figures $2 \mathrm{e}$ and S3e). WT plants were $73 \pm 5.4 \mathrm{~cm}$ in height, while OE-5, OE-6 and OE-8 plants were $106 \pm 7.0 \mathrm{~cm} 101 \pm 3.1 \mathrm{~cm}$ and $101 \pm 4.8 \mathrm{~cm}$, respectively (Figure 2e), an increase of $45 \%, \sim 38 \%$ and $36 \%$ compared to the WT. The number of mainstem internodes was also significantly increased in transgenic plants with an average of 26, while WT is 20 (Figure S3e). 
(a)

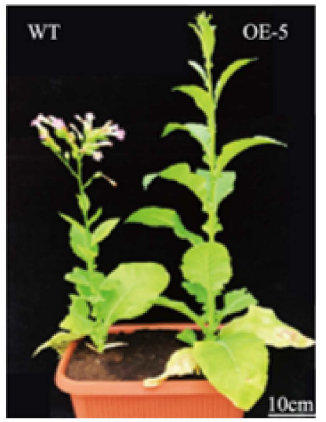

(d)

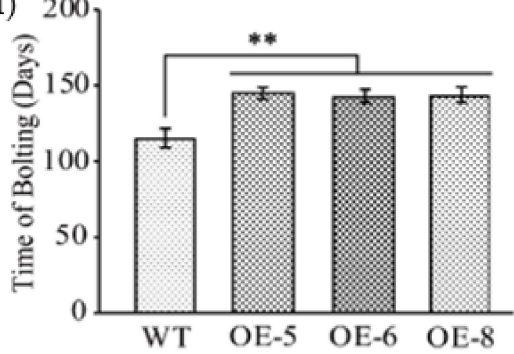

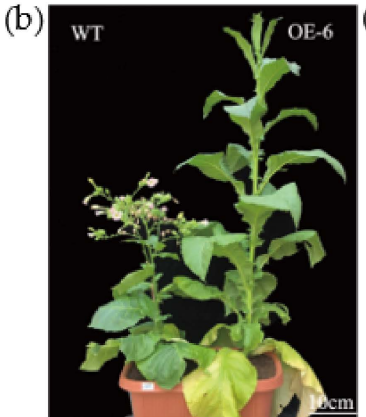

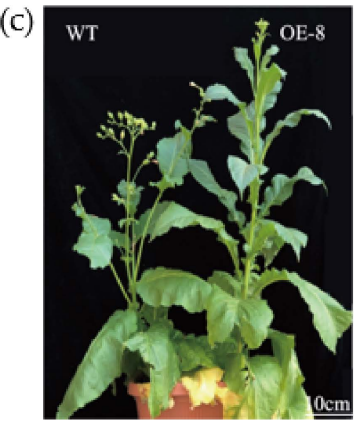

(e)

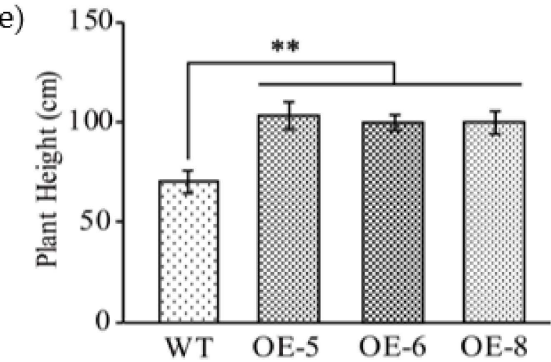

Figure 2. Flowering time and plant height analysis in GhKTI12 transgenic plants. (a-c) Plant height (Scale $=10 \mathrm{~cm})$ and initial bolting morphology of WT and GhKTI12 transgenic tobacco. Statistical comparison of morphological analysis in (d) Initial bolting time. (e) Plant height $(\mathrm{Scale}=10 \mathrm{~cm})$. Bars in the graph show the standard mean error. Asterisks indicates significant differences between wild type (WT) and GhKTI12 transgenic plants analyzed by Student's $t$-test, $p<0.01\left({ }^{* *}\right)$. Data were collected from 10 representative plants.

In order to determine the mechanism of morphological changes in transgenic plants at the cytological level, we observed the number, size, and longitudinal length of stem epidermal cells. We found that the cell number in the main stem was $55 \%$ higher in OE plants compared to the WT, but the cell size was smaller and longitudinal cell length was shorter (Figure S3f,g). The average cell size of OE plants with $64 \%$ of WT and cell length only $77 \%$ as well. These results suggest that increased plant height in GhKTI12 OE plants was mainly caused by increased cell proliferation rather than cell expansion in the mainstem internode.

\subsection{Overexpression of GhKTI12 Could Increase Leaf Size by Regulating Cell Division}

All transgenic plants were larger than WT plants at the flowering stage, particularly the size of the leaf in the middle stem position. The average leaf area was $\sim 36 \%$ and $34 \%$ higher in OE-6 and OE-8, respectively, compared to the WT.

Ten plants from each line were randomly selected for leaf measurements. The length and width were measured for three leaves in different leaf positions (5th, 8th, and 12th). The average leaf length in transgenic plants was $4.83 \mathrm{~cm}, 4.79 \mathrm{~cm}$, and $4.60 \mathrm{~cm}$ at the 5 th, 8 th and 12 th position, respectively. This was $\sim 36 \%, 41 \%$, and $59 \%$ higher than the corresponding leaves from WT plants (Figure 3a). Although leaf width was also increased in OE plants compared to the WT, the differences were not significant (Figure 3b). These results suggest that the overexpression of GhKTI12 enhanced leaf length.

Plant organ development size was primarily determined by cell proliferation and cell expansion. To analyze the mechanism of leaf size changes in transgenic plants at the cytological level, we observed cell number and size in the third leaf of 45- to 60-day-old plants under the microscope. The average number of epidermis cells was significantly increased and average cell size was decreased in transgenic plants compared to the WT (Figure 3c); cell number was increased by $\sim 55 \%$, a change which was accompanied by reduced cell size of $\sim 18 \%$ (Figure $3 \mathrm{~d}$ ). These results indicate that KTI12 played a positive role in regulating leaf length by increasing cell proliferation rather than cell expansion. 
(a)

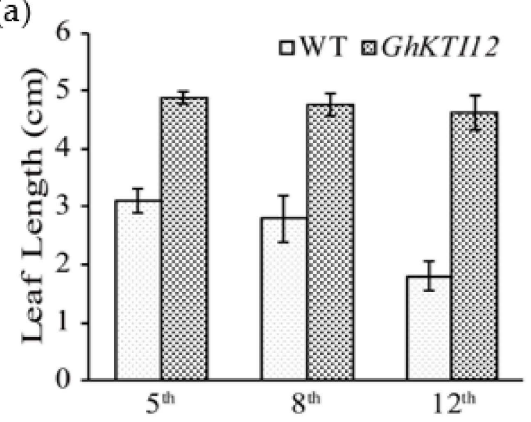

(c)

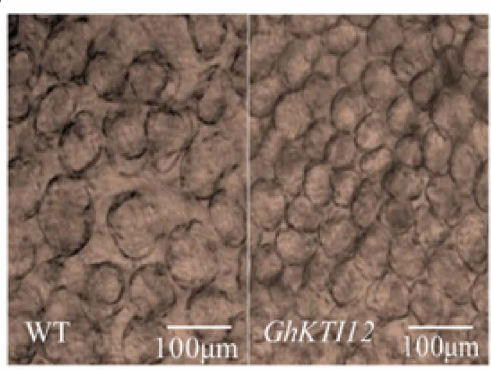

(b)

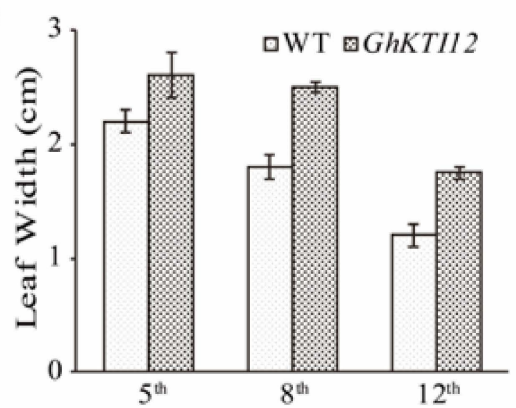

(d)

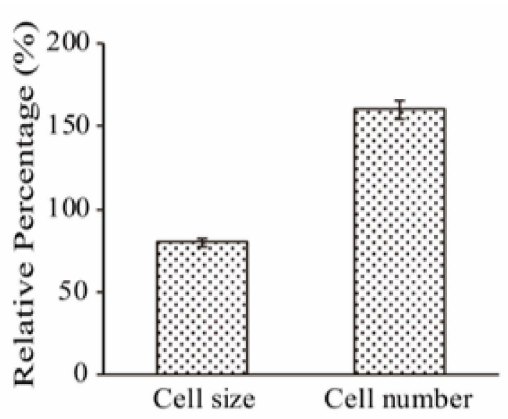

Figure 3. Effect of GhKTI12 on tobacco leaf development. (a,b) Comparison of leaves size from three different positions (5th, 8th, and 12th) between WT and GhKTI12 transgenic plants from 4-month-old plants, the leaf length and leaf width were measured $(n=10)$. (c) Microscopic observation of palisade cell in the upper epidermis of third leaf in wild type and transgenic plant. (Bars $=100 \mathrm{um}$.) $(\mathrm{n}=5)$. (d) Relative percentage of epidermis palisade cell number and cell size in GhKTI12 transgenic tobacco compared with wild type $(n=10)$. All data was taken from T2 generation. Bars in the graph show the standard mean error. Asterisks indicates significant differences between wild type (WT) and GhKTI12 transgenic plants analyzed by Student's $t$-test, $p<0.01$.

Taken together, our results support that GhKTI12 is involved in the positive regulation of leaf epidermal cell division and proliferation for leaf area enlargement in transgenic tobacco plants.

\subsection{Overexpression GhKTI12 Could Increase Plant Biomass and Seed Yield in Tobacco}

All of the OE plants were larger than WT plants at the reproductive stage (Figure S4a-c), particularly in the root system (Figure $4 \mathrm{a}-\mathrm{c}$ ), and OE plants additionally developed more capsules (Figure S4d-f). Statistical analyses indicated that the overexpression of GhKTI12 in tobacco significantly increased the biomass in normal growth conditions (Tables 1 and S2). Compared to WT plants, the average whole plant fresh and dry weights were increased by $33 \%$ and $34 \%$ in transgenic plants (OE-5, OE- 6 and OE- 8 ), respectively. The root volume of OE-5, OE-6 and OE-8 was also increased to twice the volume of WT plants (Figure $4 a-c)$. The average root fresh and dry weight were increased by $33 \%$ and $52 \%$ in transgenic lines, respectively (Table 1). These results suggest that overexpression of GhKTI12 could promote root development to increase root volume.

OE-5, OE- 6 and OE- 8 also produced more flowers and capsules in the reproductive stage. The average capsule number per ten plants in OE-5, OE-6 and OE- 8 was 114, 128 and 142 , which contributed to an increase of $35 \%, 40 \%$ and $44 \%$ in net seed yield, respectively (Figure $4 \mathrm{~d}, \mathrm{e}$ ), compared to WT plants (Figure S4d-f). However, there was no significant difference in the weight of 1000 seeds between lines (Table S2). These results suggest that the number of capsules per plant played a major role in increasing seed yield. 
(a)

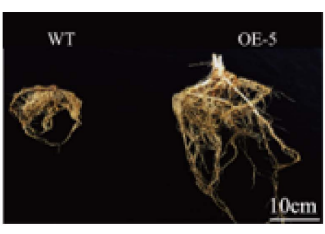

(d)

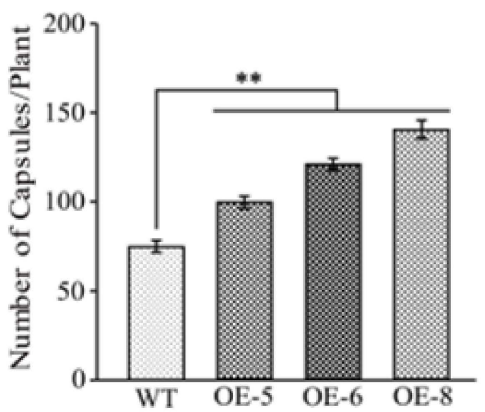

(b)

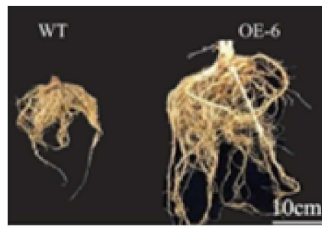

(c)

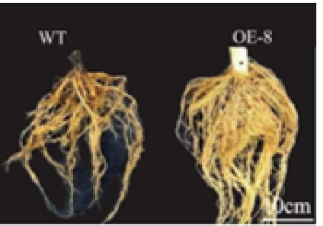

(e)

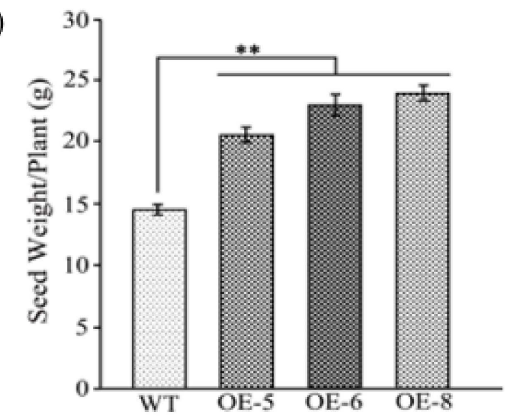

Figure 4. Analysis of root morphological and seed production in transgenic plants. (a-c) Comparison of roots morphological between wild type and GhKTI12 transgenic plants. (d) Total number of capsules per each plant $(n=10)$. (e) Seed yield per individual tobacco plant $(n=10)$. Bars in the graph show the standard mean error. Asterisks indicates significant differences between wild type (WT) and GhKTI12 transgenic plants analyzed by Student's $t$-test $p<0.01(* *)$. Data were collected from 10 representative plants.

Table 1. Comparison of biomass production between GhKTI12 transgenic and wild type (WT) tobacco plants.

\begin{tabular}{ccccccccc}
\hline \multirow{2}{*}{ Genotype } & \multicolumn{4}{c}{ Fresh Weight (g) } & \multicolumn{3}{c}{ Dry Weight (g) } \\
\cline { 2 - 9 } & Leaves & Stem & Root & $\begin{array}{c}\text { Total } \\
\text { Weight (g) }\end{array}$ & Leaves & Stem & Root & $\begin{array}{c}\text { Total } \\
\text { Weight (g) }\end{array}$ \\
\hline WT & $110.66 \pm 9.11$ & $148.73 \pm 14.23$ & $20.47 \pm 2.03$ & 279.86 & $26.05 \pm 2.11$ & $29.93 \pm 2.06$ & $3.76 \pm 0.71$ & 59.74 \\
OE-5 & $173.15 \pm 13.18$ & $232.58 \pm 15.02$ & $32.01 \pm 2.92$ & 437.74 & $40.74 \pm 3.98$ & $43.26 \pm 3.80$ & $8.26 \pm 0.94$ & 92.26 \\
OE-6 & $163.93 \pm 15.16$ & $220.19 \pm 17.81$ & $30.3 \pm 2.82$ & 414.42 & $38.57 \pm 3.56$ & $43.46 \pm 3.72$ & $7.82 \pm 0.72$ & 89.85 \\
OE-8 & $165.01 \pm 14.48$ & $221.64 \pm 17.67$ & $30.52 \pm 2.65$ & 417.17 & $38.82 \pm 3.64$ & $44.42 \pm 3.17$ & $7.87 \pm 0.97$ & 91.11 \\
\hline
\end{tabular}

Data were collected at harvesting time. Standard deviation (SD) were calculated from mean value of 10 sample plants.

\subsection{Overexpression of GhKTI12 Could Affect the Contents of Chlorophyll, Sucrose and Starch in} Tobacco Leaves

In OE plants, leaves appeared greener from the middle to the 10th leaf upper positions than those of WT plants, but had a comparable yellow color in the 6th leaf lower position. Chlorophyll contents were increased approximately $12 \%$ and $35 \%$ at the 6 th and 10th position, respectively, in transgenic plants (Figure 5a). Chlorophyll content analysis showed that overexpression of GhKTI12 could enhance chlorophyll production during leaf development in transgenic tobacco plants.

In order to understand the mechanism of higher yield and the accumulation of photosynthetic products in transgenic plants, sucrose and starch contents were analyzed in the 5th-10th leaves of 60-day-old OE and WT plants. The leaf sucrose content was gradually increased in the 5 th to 8th leaf of transgenic plants, and declined to $13 \mathrm{mg} / \mathrm{g}$ fresh weight (FW) in transgenic younger leaves at the 9th position, approximately $16 \%$ lower than in the 9th leaf of WT plants (Figure 5b). Conversely, the leaf starch content dramatically increased from the 5th to 10th leaf. The average starch content in OE-5, OE-6 and OE-8 leaves was 1.3-1.45 times higher compared to WT plants. There was also a more than fivefold increase in the OE younger leaf (10th position) compared to the older leaf (5th position), and an approximately threefold increase in the WT 10th leaf compared to 5th leaf (Figure 5c). These 
results suggest that overexpression of GhKTI12 could increase chlorophyll content and carbohydrate accumulation, promoting plant development and high yield.

(a)

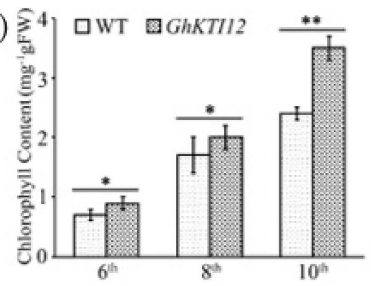

(b)

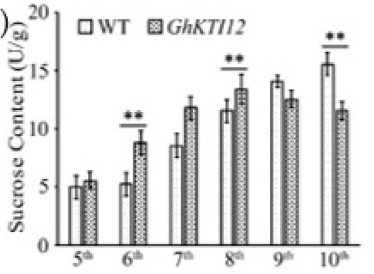

(c)

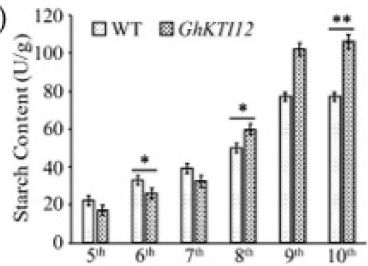

Figure 5. Contents analysis of chlorophyll, sucrose and starch in GhKTI12 transgenic tobacco leaves. (a) Chlorophyll content in GhKTI12 transgenic plants and wild-type plants $(\mathrm{n}=10)$. (b) Sucrose content in leaves at different leaf ages. (c) Starch content in leaves at different leaf ages. All data were taken from $\mathrm{T} 2$ generation. Bars in the graph show the standard mean error. Asterisks indicates significant differences between wild type (WT) and GhKTI12 transgenic plants analyzed by Student's $t$-test, $\left(^{*}\right) p<0.05 ;\left({ }^{* *}\right) p<0.01$.

\subsection{Differential Gene Expression Analysis in Tobacco Transcriptome}

KTI12 interacts with elongator complex to regulate gene expression. Previous results revealed that the overexpression of GhKTI12 could positively affect plant development. However, there was no significant difference in morphology traits between different transgenic lines (OE-5, OE-6 and OE-8). To explore the molecular mechanism of global gene expression changes in transgenic plants, the OE-6 and OE- 8 with most high expression of GhKTI12 gene were selected to do transcriptome analysis. The transcriptome analysis samples were shoot apical meristematic tissue (SAM) of 60-day-old plants which considered to be the tissue with the most vigorous cell division and differentiation. We identified 11,168 differentially expressed genes (DEGs) from the RNA-seq data comparison of OE-6 and OE-8 with WT plants. Among those DEGs, 2677 (24\%) were identified as core DEGs (shared by the two transgenic lines; Figure S5a, Table S3). Among the core DEGs, 518 were upregulated and 406 were downregulated (Figure S5b-d; Table S4).

\subsection{Transcriptome Changes Associated with Plant Growth and Development Process}

Gene enrichment analysis was performed using single species enrichment analysis (SEA) to gain insight into core DEG functions. The 518 core upregulated genes were enriched in $28 \mathrm{GO}$ functional groups; these included six cellular components, 11 biological processes, and 11 molecular functions (Figure 6a, Table S5). The terms were related to plant growth and development.

Enriched cellular components included the highly significant $(p$-value $<0.05, \mathrm{FDR}<0.001)$ respiratory chain (GO:0070469), lysosome (GO:0005764), endoplasmic reticulum lumen (GO:0005788), lytic vacuole (GO:0000323), and "microtubule organizing center part" (GO:0044450). Significantly enriched biological processes were related to immune and heat response, namely regulation of systemic acquired resistance (GO:0010112) and response to heat (GO:0009408). Significantly enriched molecular functions were unfolded protein binding (GO:0051082), glutathione transferase activity (GO:0004364), and $\alpha$-L-fucosidase activity (GO:0004560) (Figure 6a; Table S5).

From this enrichment analysis of DEGs, we identified nineteen upregulated genes related to the respiratory chain, lysosome-stored cysteine proteases, microtubule-associated protein and $\alpha$-L-fructosidase activity (Figure $6 \mathrm{~b}$ ). There were ten respiratory chain genes, which included three alternative oxidative $(A O X)$ genes $(A O X 1, A O X 2$ and $A O X / A O M I)$, four cytochrome c-dependent genes (CYTC-2, COX, UQCRX/QCR9 and petA), two ATPase inhibitor proteins (At2g27730 and F1F0-ATPase inhibitor protein), and the transmembrane protein TETRASPANIN 8 (TET8). There were five lysosome-stored cysteine protease genes: Cathepsin B-like cysteine proteinase 5 (Cpr-5), senescence-associated gene (SAG12-2), thiol protease SEN102 (SEN102), cathepsin B-like cysteine proteinase (AT4G01610) and cathepsin 
F-like cysteine proteinase $(R D 21)$. The three microtubule-associated proteins (MAPs) were Katanin p80 (KTN80), $\mathrm{Ca}^{2+}$-binding protein $1(\mathrm{CP} 1)$, and $\mathrm{Ca}^{2+}$ binding protein with one EF-Hand Motif (KIC). Additionally, one gene of $\alpha$-L-fucosidase activity is FUC1.

(a)

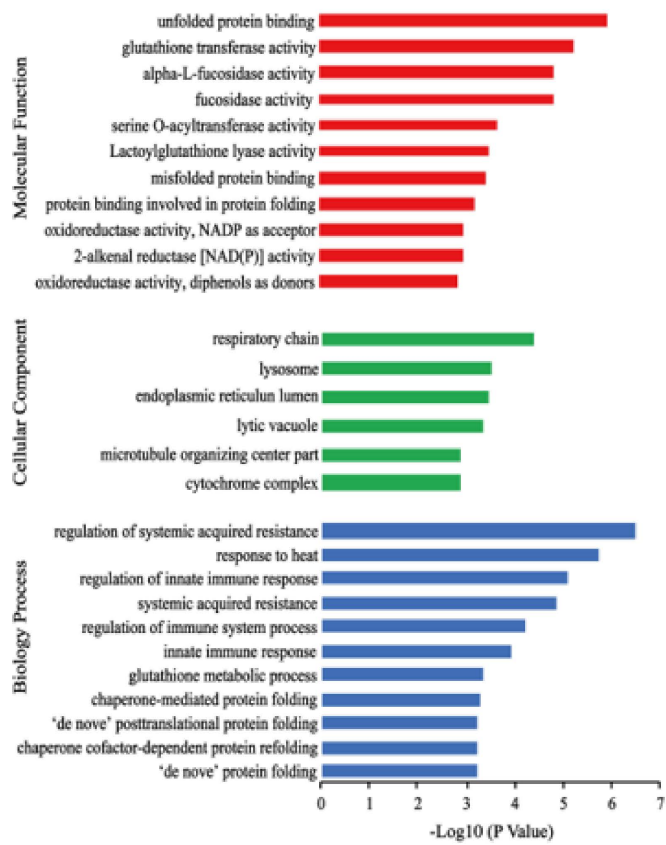

(b)

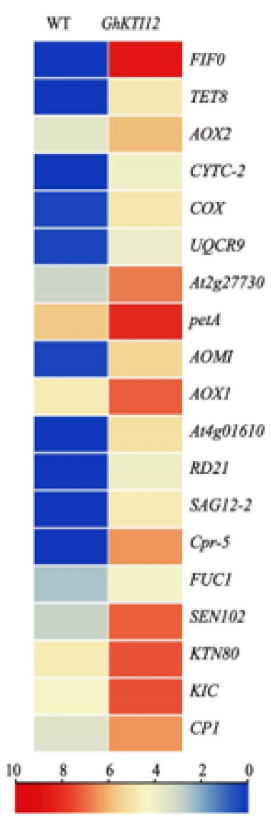

Figure 6. Analysis of upregulated genes in GhKTI12 transgenic plants. GO Histogram of Annotated (a) upregulated genes (URGs) in three different functional categories. (b) The heat map of DEGs associated with enriched cellular components.

Among these, thirteen significantly upregulated genes (F1F0, TET8, CYTC-2, COX, SAG12-2, RD21, Cpr-5, CP1, KIC, KTN80, AOX2, AOMI and AOX1A) were used to validate gene expression patterns in a mixed sample of OE-6 and OE-8 SAM by qRT-PCR. Compared to relative expression levels in the WT mixed samples, all measured genes were significantly upregulated in transgenic samples (Figure S6). These results validate the RNA-seq results in this system and further suggest that GhKTI12 could regulate some key genes related to plant cellular and organellar development, ultimately affecting the growth and development of the whole plant.

\subsection{Transcriptome Changes Associated with Flowering Time}

Flowering time was significantly delayed in OE plants compared to the WT. To understand changes in gene regulation associated with delayed flowering in transgenic plants, flowering-related genes were identified among core DEGs. There were 12 enriched GO molecular function groups annotated to 406 downregulated DEGs involved in flowering (Figure 7a; Table S6). The most enriched GO groups were related to RNA polymerase II regulatory sequence-specific DNA binding (Figure 7a).

Among those 406 DEGs, there were 10 significantly downregulated genes related to flower development and belonging to the MADS-box group, namely AGL6, AGL8, and AGL14 from the AGAMOUS (AG) family, and AP1 (APETALA1), AP3 (APETALA3), SEP1 (SEPALLATA1), SEP2 (SEPALLATA2), MADS6, TDR4 (a AGL8 homolog), and CMB1 (Figure $7 \mathrm{~b}$ ). According to the importance of their regulation in flowering time, eight genes (AGL6, AGL8, AP1, AP3, AGL14, SEP.1, SEP.2, MADS6) from 10 significantly downregulated genes were selected for expression level quantification in a mixed sample of OE-6 and OE-8 SAM with qRT-PCR. The results show that those eight genes were significantly downregulated in the OE plants compared with the WT (Figure S7). Similarly, some genes related to magnesium binding, terpene synthase activity, and voltage-gated ion channel activity were also slightly downregulated in OE plants (Figure 7a). These results suggest 
that delayed flowering was caused by the downregulation of flower development-related genes in GhKTI12 OE plants.

(a)

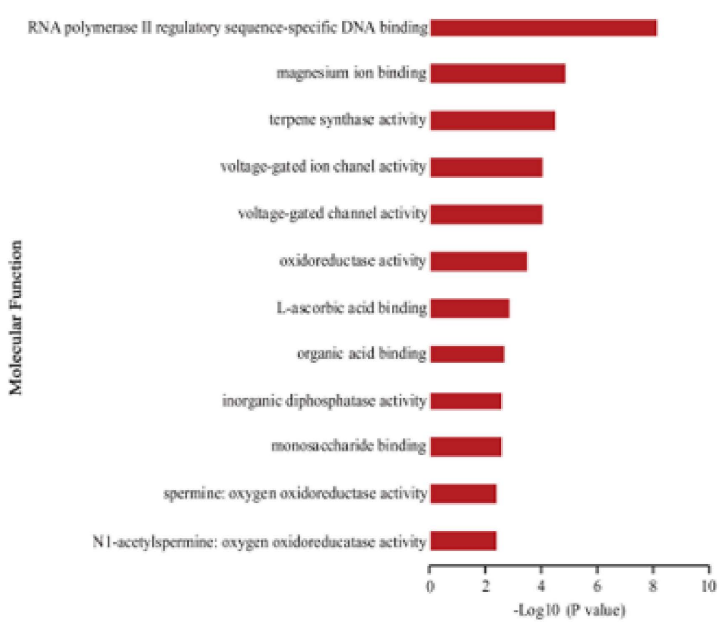

(b)

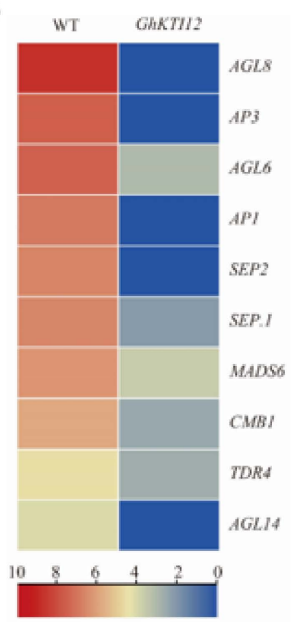

Figure 7. Analysis of downregulated gene related to plant flowering in GhKTI12 transgenic plants. (a) Top 12 GO enrichment analysis of downregulated genes (DRGs) in molecular function. (b) The heat map of DGEs associated with flowering time related genes.

\section{Discussion}

As an essential component for elongator-dependent tRNA modification [9,14], KTI12 and its homolog, DRL1, can positively regulate plant meristem activity and organ growth by modulating both cell division and differentiation in Arabidopsis [4,8]. Mutants for AtDRL1, AtKTI12, and AtELP3 showed abnormal leaf shape and smaller leaf size due to a reduction in leaf palisade cell number and increase in cell size [4,8,9,12,26-28]. However, the overexpression of KTI12 could prolong the vegetative growth stage and promote a larger plant size in Arabidopsis and other plants [29,30].

In this study, OE-5, OE-6 and OE-8 developed in a longer vegetative stage and had larger leaves, increased plant height, larger root systems, and a higher yield. Biochemical analysis revealed that transgenic lines contained more chlorophyll and accumulated more sucrose and starch in functional leaves. In order to explore the underlying molecular mechanism of morphological changes in the OE lines, we performed RNA-seq analysis of the shoot apical meristem (SAM). A total of 2677 genes ( $24 \%$ of all genes differentially expressed in either OE line) were identified as core differentially expressed genes (DEGs) in GhKTI12 transgenic tobacco (Figure S5a). Among those, 518 and 406 genes were upregulated and downregulated, respectively (Figure S5d; Table S3). Analysis of the core DEGs showed that some plant development-related genes were upregulated and some flowering-related genes were downregulated in GhKTI12 transgenic plants. These genes were enriched in $40 \mathrm{GO}$ functional groups, including cell components, molecular functions, and biological processes.

\subsection{Overexpression of GhKTI12 Could Upregulate Cellular Components Related Genes to Promote Plant Growth}

Among the GO enriched cellular components genes in GhKTI12 transgenic tobacco plants, nineteen genes were significantly upregulated and related to plant development which belong to respiratory chain, microtubule organizing center part, lysosome and $\alpha$-L-fucosidase activity (Figure 6b).

The respiratory chain-associated genes participate in cell-to-cell communication processes during cell morphogenesis, motility, and fusion in plants. These genes mainly regulate growth, division, differentiation, movement, and respiratory maintenance of cells, as well as cell wall stability in plant development [31], such as AOX, TET, CYTC, COX, F1F0 et al. AOX could interact with other cellular signals [32,33] to affect plant biomass 
production [34], plant growth and photosynthesis rates [35,36], and biotic/abiotic stress tolerance [37-39]. TET8 could regulate plant cell differentiation and maintain the cell membrane microenvironment [40], TET5 and TET6 could negatively regulate plant cell proliferation to affect leaf shape and root growth [41]. CYTC-2 and COX could regulate cell respiration and apoptosis [42]. F1F0 regulates cell proliferation and survival [43]. In addition, the mutation of CYTC-1 and CYTC-2 results in smaller rosettes with a significant decrease in parenchymatic cell size and delayed plant development due to the lower mitochondrial respiration rate [44]. These upregulated genes affected cell development in GhKTI12 transgenic tobacco plants to grow in a bigger morphology and higher yield.

The microtubule organizing center part related genes directly regulated cell development, such as KTN80, CP1 and KIC. KTN80 belongs to the WD-repeat protein superfamily, which is involved in the rapid reorganization of cellular microtubule arrays [45] to regulate cell division and motility [46]. ktn80 mutant Arabidopsis leaves display abnormal epidermal cells due to intertwined and twisted microtube formation [45]. CP1 and KIC are $\mathrm{Ca}^{2+}$-binding proteins involved in cell division by interacting with Kinesin-like calmodulin binding protein (KCBP) [47-49]. Overexpression of KIC in Arabidopsis cou4ld regulate leaf trichome morphogenesis through facilitating the microtube-stimulated KCBP protein [50]. Otherwise, increased cellular $\mathrm{Ca}^{2+}$ levels could promote primary root growth by mediating auxin signaling in KIC transgenic plants [51-53]. So the reason of bigger morphology in GhKTI12 transgenic tobacco lines maybe caused by the upregulation of microtubule organizing center part related genes (Figures 6a and S6). Meanwhile, larger root systems in GhKTI12 transgenic tobacco lines may be due to upregulation of CP1 and KIC.

In the lysosome, the cathepsins are cysteine proteases of papain-like $C 1 A$ involved in multiple physiological processes such as plant growth seed germination, another development, programed cell death (PCD), abiotic stress, and immunity [54]. In our GhKTI12 transgenic tobacco lines, five cathepsin proteins genes were upregulated, such as $\mathrm{Cpr}-5$, SAG12-2, SEN102, AT4G01610 and RD21A. These genes could regulate leaf senescence and plant growth. For example, the senescence-specific cysteine protease gene $S A G 12$ negatively regulates leaf cell death. The downregulation of OsSAG12-1 resulted in stress-induced cell death in transgenic rice RNAi lines [55]. Several studies have also reported that the expression of a cytokinin biosynthetic enzyme under the control of the AtSAG12 promoter delays senescence in Arabidopsis, lettuce, and wheat [56-58]. In our study, the chlorophyll content in upper leaves (12th leaf) was higher in the OE lines than in the WT, consequently delaying leaf senescence in transgenic plants. It has been also noted that the total amount of carbon fixation in crops increases with prolonged periods of photosynthesis and leaf senescence delay [59]. Therefore, a delay in leaf senescence with increased chlorophyll content in transgenic leaves may be due to the upregulation of NtSAG12 protein in GhKTI12 transgenic tobacco plants. A prolonged life stage with increased chlorophyll and a delay in leaf senescence could increase the photosynthetic rate and promote plant development in tobacco overexpressing GhKTI12.

Combined gene expression profiles with morphology data demonstrated that overexpression of GhKTI12 in tobacco could positively regulate cellular component-related genes to promote cell proliferation and plant development. We propose that these upregulated genes promote plants' development of larger leaves, increased plant height, and larger root systems compared to the WT.

\subsection{Overexpression of GhKTI12 Could Downregulate Flowering Related Genes to Delay Tobacco Flowering Time}

OE-5, OE-6 and OE-8 plants displayed late flowering, delayed by 28-30 days compared with the WT (Figure 2d). This is consistent with Arabidopsis elp1 knockout mutants and ELP1 overexpression plants [2,3,14]. In order to explore the underlying molecular mechanism of delayed flowering in GhKTI12 transgenic tobacco plants, 10 downregulated genes were identified by RNA-seq analysis in OE-6 and OE-8 lines. Eight of the downregulated genes were MADS-box transcription factor family proteins involved in flowering 
time regulation, such as $A P 1, A P 3, A G L 6, A G L 8, A G L 14, S E P$ et al. The gene expression pattern was validated by qRT-PCR (Figures $7 \mathrm{~b}$ and 57 ; Table S6).

The $A P 1$ and $A P 3$ can act either alone or in combination to determine the activation of the floral organ-specific gene in specific regions of the developing flower [60,61]. AP1 plays a crucial role in the transition from vegetative to reproductive phase and floral development [62], and activates the expression of the B-class homeotic genes. AP3 determines the identity of petals and stamens [63]. Overexpression of AP1 causes early-flowering phenotypes in the Arabidopsis [64], apple [65] and soybean [66].

Furthermore, AGL6, AGL8 and AGL14 are pivotal in promoting floral meristem development by limiting stem cell proliferation $[67,68]$. AGL6 has a similar function to AP1 and SEP in Arabidopsis [69]. Accordingly, the overexpression of AGL6 in Arabidopsis and overexpression of the SEP-like gene TaMADS1 in wheat [70] exhibited early flowering in transgenic plants. Recent studies also demonstrated that the overexpression of xal2/AGL14 causes early flowering, whereas a knockout mutant shows late flowering in Arabidopsis [71].

These results proved that a delayed flowering time and longer vegetative stage in GhKTI12 transgenic plants were caused by the downregulation of MADS-box genes such as AP1, AGL6, AGL14, and SEP genes. Based on the molecular mechanism of morphology and later flowering phenotype in transgenic plants, we hypothesize that the overexpression of GhKTI12 in tobacco could create a strong basis for plant reproduction and yield by increasing plant size and delaying the flowering time with a longer vegetative stage.

\subsection{Overexpression of GhKTI12 Could Increase Plants Biomass and Seed Yield}

Biomass and seed yield were significantly increased in GhKTI12 OE lines. The average dry weight of leaves and stems increased by $\sim 34 \%$ in OE-5, OE-6 and OE-8 (Tables 1 and S2), and the average fresh and dry weight of roots were increased by $33 \%$ and $52 \%$, respectively, in both OE-5, OE-6 and OE-8 (Tables 1 and S2). These results suggest that the overexpression of GhKTI12 promotes whole plant development to increase biomass. Transgenic plants additionally produced more flowers and capsules; the average capsule number per ten plants in OE-5, OE-6 and OE-8 was 114, 128 and 142, contributing to an increase of 35\%, $40 \%$ and $44 \%$ net seed yield, respectively (Figure $4 \mathrm{~d}, \mathrm{e}$ ). However, there was no significant difference in the average weight of 1000 seeds between lines (Table S2).

As the main product of photosynthesis, sucrose is transported from the source organ to the sink organ in plants and is related to biomass and yield [72]. We found increased chlorophyll content in younger leaves at the top canopy of transgenic plants and a corresponding decrease in the accumulation of sucrose and starch (Figure 5b,c). This may be due to photosynthetic carbon partitioning between sucrose and starch in the cytoplasm and chloroplasts of leaves, respectively [73-75]. Therefore, the overexpression of GhKTI12 could increase starch accumulation via sucrose breakdown in younger leaves of the top canopy before floral transition, which may contribute to an improved photosynthetic rate, and in turn to an increased seed yield.

Furthermore, the cellular component-related protein RD21 physically interacts with water-soluble chlorophyll proteins, which are involved in embryo development and seed formation via controlling cell death during the flower development progress [76]. Therefore, high yield in GhKTI12 overexpressing tobacco may also be caused by the upregulation of RD21. Taken together, these results suggest that the overexpression of GhKTI12 could improve seed yield and biomass production by regulating gene expression involved in various biological processes including cell division, leaf senescence, programed cell death, photosynthesis, and embryo development.

\section{Conclusions}

In conclusion, the overexpression of GhKTI12 in tobacco led to significant variation in agriculturally important phenotypes, increasing cell proliferation and organ growth, delaying flowering time, and increasing plant height, seed yield, and biomass production. 
The OE-5, OE-6 and OE-8 lines with significantly improved phenotypes illustrate that GhKTI12 acts as a super-gene to positively regulate plant development and yield. Thus, GhKTI12 has broad prospects for the genetic improvement of crops in the future.

Supplementary Materials: The following supporting information can be downloaded at: https: / / www.mdpi.com/article/10.3390/genes13030426/s1, Figure S1: Bioinformatic analysis of GhKTI12, Figure S2: Identification of GhKTI12 transgenic plants, Figure S3: Morphology analysis and stem cell observation of GhKTI12 transgenic plants, Figure S4: Observation of morphology and capsule number in GhKTI12 transgenic plants. Figure S5: Analysis of differentially expressed genes (DEGs) in GhKTI12 transgenic plants, Figure S6: qRT-PCR analysis of cellular protein genes in GhKTI12 transgenic plants and WT plants, Figure S7: qRT-PCR analysis of downregulated genes related to plant flowering in GhKTI12 transgenic plants and WT plants, Table S1: List of primers used in this study, Table S2: Comparison of biomass production, and seed yield between GhKTI12 transgenic and WT tobacco plants, Table S3: Core DEGs in WT and GhKTI12 transgenic samples, Table S4: Up- and downregulated DEGs in WT and GhKTI12 transgenic samples, Table S5: Enriched GO terms in upregulated DEGs in WT and GhKTI12 transgenic samples, Table S6: Enriched GO terms in downregulated DEGs in WT and GhKTI12 transgenic samples.

Author Contributions: Conceptualization, A.A.M., Y.Z., Y.G., Z.M. and R.Z.; methodology, A.A.M., Y.Z., Y.G., X.Z., C.L., P.W., Z.M. and R.Z.; software, A.A.M., Y.Z., Y.G., U.A., M.A.A., M.A. (Mubashir Abbas) and M.A. (Muhammad Askari); validation, A.A.M., Y.Z., U.A., M.A. (Mubashir Abbas), S.G., Z.M. and R.Z.; formal analysis, A.A.M., Y.Z., M.A. (Mubashir Abbas), M.A. (Muhammad Askari), C.L., S.G., Z.M. and R.Z.; writing-original draft preparation, A.A.M., Y.Z., Y.G., X.Z., M.A.A. and C.L.; writing-review and editing, A.A.M., Y.Z., Y.G., S.G., Z.M. and R.Z.; supervision, Z.M. and R.Z. All authors have read and agreed to the published version of the manuscript.

Funding: This work was supported by the Swedish International Development Cooperation Agency (Sida) for Women in Science for the Developing World (OWSD) PhD Fellowships, Italy; the National Natural Science Foundation of China [grant numbers 31871681]; the "intergovernmental international scientific and technological innovation cooperation" of the national key R\&D program, MOST of China [grant numbers 2021YFE0101400].

Institutional Review Board Statement: Not applicable.

Informed Consent Statement: Not applicable.

Data Availability Statement: The datasets generated during and/or analyzed during the current study are available from the corresponding author on reasonable request.

Acknowledgments: We are grateful to Tao Zhu, Guoqing Sun, Wenzhong Deng and Congwei Wang for technical assistance.

Conflicts of Interest: The authors declare no conflict of interest.

\section{References}

1. Butler, A.R.; White, J.H.; Folawiyo, Y.; Edlin, A.; Gardiner, D.; Stark, M.J. Two Saccharomyces cerevisiae genes which control sensitivity to G1 arrest induced by Kluyveromyces lactis toxin. Mol. Cell Biol. 1994, 14, 6306-6316.

2. Frohloff, F.; Fichtner, L.; Jablonowski, D.; Breunig, K.D.; Schaffrath, R. Saccharomyces cerevisiae Elongator mutations confer resistance to the Kluyveromyces lactis zymocin. EMBO J. 2001, 20, 1993-2003. [CrossRef] [PubMed]

3. Fichtner, L.; Frohloff, F.; Bürkner, K.; Larsen, M.; Breunig, K.D.; Schaffrath, R. Molecular analysis of KTI12/TOT4, a Saccharomyces cerevisiae gene required for Kluyveromyces lactis zymocin action. Mol Microbiol. 2002, 43, 783-791. [CrossRef] [PubMed]

4. Nelissen, H.; Clarke, J.H.; de Block, M.; de Block, S.; Vanderhaeghen, R. DRL1, a homolog of the yeast TOT4/KTI12 protein, has a function in meristem activity and organ growth in plants. Plant Cell 2003, 15, 639-654. [CrossRef]

5. Krutyhołowa, R.; Rhardt-Tews, A.; Chramiec-Głąbik, A.; Breunig, K.D.; Glatt, S. Fungal Kti12 proteins display unusual linker regions and unique ATPase p-loops. Curr. Genet. 2020, 66, 823-833. [CrossRef] [PubMed]

6. Wang, H.; Xu, C.; Zhang, Y.; Yan, X.; Jin, X.; Yao, X.; Chen, P.; Zheng, B. PtKTI12 genes influence wobble uridine modifications and drought stress tolerance in hybrid poplar. Tree Physiol. 2020, 40, 1778-1791. [CrossRef]

7. Leipe, D.D.; Koonin, E.V.; Aravind, L. Evolution and classification of P-loop kinases and related proteins. J. Mol. Biol. 2003, 333, 781-815. [CrossRef] [PubMed]

8. Jun, S.E.; Cho, K.H.; Hwang, J.Y.; Abdel-Fattah, W.; Hammermeister, A.; Schaffrath, R.; Bowman, J.L.; Kim, G.T. Comparative analysis of the conserved functions of Arabidopsis DRL1 and yeast KTI12. Mol. Cells 2015, 38, 243-250. [CrossRef] 
9. Nelissen, H.; Fleury, D.; Bruno, L.; Robles, P.; de Veylder, L.; Traas, J.; Micol, J.L.; van Montagu, M.; Inze, D.; van Lijsebettens, M. The elongata mutants identify a functional Elongator complex in plants with a role in cell proliferation during organ. Proc. Natl. Acad. Sci. USA 2005, 102, 7754-7759. [CrossRef]

10. Mehlgarten, C.; Prochaska, H.; Hammermeister, A.; Abdel-Fattah, W.; Wagner, M.; Krutyhołowa, R.; Jun, S.E.; Kim, G.T.; Glatt, S.; Breunig, K.D.; et al. Use of a yeast tRNase killer toxin to diagnose KTI12 motifs required for tRNA modification by elongator. Toxins 2017, 9, 272. [CrossRef]

11. Petrakis, T.G.; Søgaard, T.M.; Erdjument-Bromage, H.; Tempst, P.; Svejstrup, J.Q. Physical and functional interaction between Elongator and the chromatin-associated KTI12 protein. J. Biol. Chem. 2005, 280, 19454-19460. [CrossRef] [PubMed]

12. Nakai, Y.; Horiguchi, G.; Iwabuchi, K.; Harada, A.; Nakai, M.; Hara-Nishimura, I.; Yano, T. tRNA Wobble Modification AffectsLeaf Cell Development in Arabidopsis thaliana. Plant Cell Physiol. 2019, 60, 2026-2039. [CrossRef]

13. Mehlgarten, C.; Jablonowski, D.; Wrackmeyer, U. Elongator function in tRNA wobble uridine modification is conserved between yeast and plants. Mol Microbiol. 2010, 76, 1082-1094. [CrossRef]

14. Chen, P.; Jäger, G.; Zheng, B. Transfer RNA modifications and genes for modifying enzymes in Arabidopsis thaliana. BMC Plant Biol. 2010, 14, 201. [CrossRef]

15. Cho, K.H.; Choi, H.; Seki, M.; Jun, S.E.; Yi, Y.B.; Shinozaki, K.; Tsukaya, H.; Kim, G.T. DRL1 regulates adaxial leaf patterning shoot apical meristem activity in Arabidopsis. J. Plant Biol. 2007, 50, 467-474. [CrossRef]

16. Chen, Z.; Zhang, H.; Jablonowski, D.; Zhou, X.; Ren, X.; Hong, X.; Schaffrath, R.; Zhu, J.K.; Gong, Z. Mutations in ABO1/ELO2, a Subunit of Holo-Elongator, Increase Abscisic Acid Sensitivity and Drought Tolerance in Arabidopsis thaliana. Mol. Cell. Biol. 2006, 26, 6902-6912. [CrossRef] [PubMed]

17. Zhou, X.; Hua, D.; Chen, Z.; Zhou, Z.; Gong, Z. Elongator mediates ABA responses, oxidative stress resistance and anthocyanin biosynthesis in Arabidopsis. Plant J. 2009, 60, 79-90. [CrossRef]

18. Bottino, P.J.; Raineri, D.; Nester, E.W.; Gordon, M.P. Agrobacterium-mediated DNA transfer. J. Tissue Cult. Methods 1989, 12, 135-138. [CrossRef]

19. Wang, H.; Nagegowda, D.A.; Rawat, R.; Bouvier-Navé, P.; Guo, D.; Bach, T.J.; Chye, M.L. Overexpression of Brassica juncea wild-type and mutant HMG-CoA synthase 1 in Arabidopsis up-regulates genes in sterol biosynthesis and enhances sterol production and stress tolerance. Plant Biotechnol. J. 2012, 10, 31-42. [CrossRef]

20. Livak, K.J.; Schmittgen, T.D. Analysis of relative gene expression data using real-time quantitative PCR and the 2(-Delta Delta C(T)) Method. Methods 2001, 25, 402-408. [CrossRef]

21. Parry, C.; Bblonquist, J.M., Jr.; Bugbee, B. In situ measurement of leaf chlorophyll concentration: Analysis of the optical/absolute relationship. Plant Cell Environ. 2014, 37, 2508-2520. [CrossRef] [PubMed]

22. Kalve, S.; Saini, K.; Vissenberg, K.; Beeckman, T.; Beemster, G. Transverse sectioning of Arabidopsis thaliana leaves using resin embedding. Bio-Protocol 2015, 5, e1592. [CrossRef]

23. Chen, C.; Chen, H.; Zhang, Y.; Thomas, H.R.; Frank, M.H.; He, Y.; Xia, R. TBtools: An Integrative Toolkit Developed for Interactive Analyses of Big Biological Data. Mol. Plant. 2020, 13, 1194-1202. [CrossRef] [PubMed]

24. Tian, T.; Liu, Y.; Yan, H.; You, Q.; Yi, X.; Du, Z.; Xu, W.; Su, Z. agriGO v2.0: A GO analysis toolkit for the agricultural community, 2017 update. Nucleic Acids Res. 2017, 45, W122-W129. [CrossRef] [PubMed]

25. Deng, W.; Wang, Y.; Liu, Z.; Cheng, H.; Xue, Y. HemI: A Toolkit for Illustrating Heatmaps. PLoS ONE 2014, 9, e111988. [CrossRef] [PubMed]

26. Nelissen, H.; de Groeve, S.; Fleury, D.; Neyt, P.; Bruno, L.; Bitonti, M.B. Plant Elongator regulates auxin-related genes during RNA polymerase II transcription elongation. Proc. Natl. Acad. Sci. USA 2010, 107, 1678-1683. [CrossRef]

27. Huang, B.; Johansson, M.J.; Bystrom, A.S. An early step in wobble uridine tRNA modification requires the Elongator complex. RNA 2005, 11, 424-436. [CrossRef] [PubMed]

28. Zhu, M.; Li, Y.; Chen, G.; Ren, L.; Xie, Q.; Zhao, Z.; Hu, Z. Silencing SlELP2L, a tomato Elongator complex protein 2-like gene, inhibits leaf growth, accelerates leaf, sepal senescence, and produces dark-green fruit. Sci. Rep. 2015, 5, 7693. [CrossRef] [PubMed]

29. Kuittinen, H.; Sillanpää, M.J.; Savolainen, O. Genetic basis of adaptation: Flowering time in Arabidopsis thaliana. Theor. Appl. Genet. 1997, 95, 573-583. [CrossRef]

30. Pouteau, S.; Ferret, V.; Gaudin, V.; Leferbvre, D.; Sabar, M.; Zhao, G.; Prunus, F. Extensive phenotypic variation in early flowering mutants of Arabidopsis. Plant Physiol. 2004, 135, 201-211. [CrossRef] [PubMed]

31. Yáñez-Mó, M.; Barreiro, O.; Gordon-Alonso, M.; Sala-Valdes, M.; Sanchez-Madrid, F. Tetraspanin-enriched microdomains: A functional unit in cell plasma membranes. Trends Cell Biol. 2009, 19, 434-446. [CrossRef] [PubMed]

32. Vanlerberghe, G.C. Alternative oxidase: A mitochondrial respiratory pathway to maintain metabolic and signaling homeostasis during abiotic and biotic stress in plants. Int. J. Mol. Sci. 2013, 14, 6805-6847. [CrossRef] [PubMed]

33. Vanlerberghe, G.C.; Dahal, K.; Alber, N.A.; Chadee, A. Photosynthesis, respiration and growth: A carbon and energy balancing act for alternative oxidase. Mitochondrion 2020, 52, 197-211. [CrossRef]

34. Kuhn, K.; Yin, G.; Duncan, O.; Law, S.R.; Kubiszewski-Jakubiak, S.; Kaur, P.; Meyer, E.; Wang, Y.; Small, C.C.; Giraud, E.; et al Decreasing electron flux through the cytochrome and alternative respiratory pathways triggers common and distinct cellular responses dependent on growth conditions. Plant Physiol. 2015, 167, 228-250. [CrossRef] [PubMed] 
35. Fiorani, F.; Umbach, A.L.; Siedow, J.N. The Alternative Oxidase of Plant Mitochondria Is Involved in the Acclimation of Shoot Growth at Low Temperature. A Study of Arabidopsis AOX1a Transgenic Plants. Plant Physiol. 2005, 139, 1795-1805. [CrossRef] [PubMed]

36. Chai, T.T.; Simmonds, D.; Day, D.A.; Colmer, T.D.; Finnegan, P.M. A GmAOX2b antisense gene compromises vegetative growth and seed production in soybean. Planta 2012, 236, 199-207. [CrossRef]

37. Dutilleul, C.; Garmier, M.; Noctor, G.; Mathieu, C.; Chétrit, P.; Foyer, C.H.; de Paepe, R. Leaf mitochondria modulate whole cell redox homeostasis, set antioxidant capacity, and determine stress resistance through altered signaling and diurnal regulation Plant Cell 2003, 15, 1212-1226. [CrossRef] [PubMed]

38. Amirsadeghi, S.; Robson, C.A.; Vanlerberghe, G.C. The role of the mitochondrion in plant responses to biotic stress. Physiol. Plant 2007, 129, 253-266. [CrossRef]

39. Giraud, E.; Ho, L.H.M.; Clifton, R.; Carroll, A.; Estavillo, G.; Tan, Y.F.; Howell, K.A.; Ivanov, A.; Pogson, B.J.; Millar, A.H. The absence of alternative Oxidase1a in Arabidopsis results in acute sensitivity to combined light and drought stress. Plant Physiol. 2008, 147, 595-610. [CrossRef]

40. Liu, X.; Pan, Y.; Liu, C.; Ding, Y.; Wang, X.; Cheng, Z.; Meng, H. Cucumber Fruit Size and Shape Variations Explored from the Aspects of Morphology, Histology, and Endogenous Hormones. Plants 2020, 9, 772. [CrossRef]

41. Wang, F.; Muto, A.; van de Velde, J.; Neyt, P.; Himanen, K.; Vandepoele, K.; van Lijsebettens, M. Functional Analysis of the Arabidopsis TETRASPANIN Gene Family in Plant Growth and Development. Plant Physiol. 2015, 169, 2200-2214. [CrossRef] [PubMed]

42. Merz, S.; Westermann, B. Genome-wide deletion mutant analysis reveals genes required for respiratory growth, mitochondrial genome maintenance and mitochondrial protein synthesis in Saccharomyces cerevisiae. Genome Biol. 2009, 10, R95. [CrossRef] [PubMed]

43. Faccenda, D.; Tan, C.H.; Seraphim, A.; Duchen, M.R.; Campanella, M. IF1 limits the apoptotic-signaling cascade by preventing mitochondrial remodeling. Cell Death Differ. 2013, 20, 686-697. [CrossRef] [PubMed]

44. Welchen, E.; Hildebrandt, T.M.; Lewejohann, D.; Gonzalez, D.H.; Braun, H.P. Lack of cytochrome c in Arabidopsis decreases stability of complex IV and modifies redox metabolism without affecting complexes I and III. Biochim. Biophys. Acta 2012, 1817, 990-1001. [CrossRef] [PubMed]

45. Wang, C.; Liu, W.; Wang, G.; Li, J.; Dong, L.; Han, L.; Wang, Q.; Tian, J.; Yu, Y.; Gao, C.; et al. KTN80 confers precision to microtubule severing by specific targeting of katanin complexes in plant cells. EMBO J. 2017, 36, 3435-3447. [CrossRef]

46. Van Nocker, S.; Ludwig, P. The WD-repeat protein superfamily in Arabidopsis: Conservation and divergence in structure and function. BMC Genomics 2003, 4, 50. [CrossRef] [PubMed]

47. Bowser, J.; Reddy, A.S. Localization of a kinesin-like calmodulin-binding protein in dividing cells of Arabidopsis and tobacco Plant J. 1997, 12, 1429-1438. [CrossRef] [PubMed]

48. Smirnova, E.; Reddy, A.; Bowser, J.; Bajer, A.S. A minus end-directed kinesin-like motor protein, KCBP, localizes to anaphase spindle poles in Haemanthus endosperm. Cell Motil. Cytoskelet. 1998, 41, 271-280. [CrossRef]

49. Vos, J.W.; Safadi, F.; Reddy, A.S.; Hepler, P.K. The kinesin-like calmodulin binding protein is differentially involved in cell division Plant Cell 2000, 12, 979-990. [CrossRef]

50. Reddy, V.S.; Day, I.S.; Thomas, T.; Reddy, A.S. KIC, a novel Ca ${ }^{2+}$ binding protein with one EF-hand motif, interacts with a microtubule motor protein and regulates trichome morphogenesis. Plant Cell 2004, 16, 185-200. [CrossRef]

51. Monshausen, G.B.; Miller, N.D.; Murphy, A.S.; Gilroy, S. Dynamics of auxin-dependent $\mathrm{Ca}^{2+}$ and pH signaling in root growth revealed by integrating high-resolution imaging with automated computer vision-based analysis. Plant J. 2011, 65, 309-318. [CrossRef] [PubMed]

52. Dindas, J.; Scherzer, S.; Roelfsema, M.R.G.; von Meyer, K.; Müller, H.M.; Al-Rasheid, K.A.S.; Palme, K.; Dietrich, P.; Becker, D.; Bennett, M.J.; et al. AUX1-mediated root hair auxin influx governs SCFTIR1/AFB-type $\mathrm{Ca}^{2+}$ signaling. Nat. Commun. 2018, 9, 1174. [CrossRef] [PubMed]

53. Zhang, X.P.; Ma, C.X.; Sun, L.R.; Hao, F.S. Roles and mechanisms of $\mathrm{Ca}^{2+}$ in regulating primary root growth of plants. Plant Signal. Behav. 2020, 15, 1748283. [CrossRef]

54. Liu, H.; Hu, M.; Wang, Q.; Cheng, L.; Zhang, Z. Role of Papain-Like Cysteine Proteases in Plant Development. Front. Plant Sci. 2018, 9, 1717. [CrossRef] [PubMed]

55. Singh, S.; Giri, M.K.; Singh, P.K.; Siddiqui, A.; Nandi, A.K. Down-regulation of OsSAG12-1 results in enhanced senescence and pathogen-induced cell death in transgenic rice plants. J. Biosci. 2013, 38, 583-592. [CrossRef]

56. McCabe, M.S.; Garratt, L.C.; Schepers, F.; Jordi, W.J.; Stoopen, G.M.; Davelaar, E.; van Rhijn, J.H.; Power, J.B.; Davey, M.R. Effects of P(SAG12)-IPT gene expression on development and senescence in transgenic lettuce. Plant Physiol. 2001, 127, 505-516. [CrossRef]

57. Liu, F.; Vantoai, T.; Moy, L.P.; Bock, G.; Linford, L.D.; Quackenbush, J. Global transcription profiling reveals comprehensive insights into hypoxic response in Arabidopsis. Plant Physiol. 2005, 137, 1115-1129. [CrossRef]

58. Sykorova, B.; Kuresová, G.; Daskalova, S.; Trcková, M.; Hoyerová, K.; Raimanová, I.; Motyka, V.; Trávnícková, A.; Elliott, M.C.; Kamínek, M. Senescence-induced ectopic expression of the A. tumefaciens ipt gene in wheat delays leaf senescence, increases cytokinin content, nitrate influx, and nitrate reductase activity, but does not affect grain yield. J. Exp. Bot. 2008, 59, 377-387. [CrossRef] 
59. Thomas, H.; Howarth, C.J. Five ways to stay green. J. Exp. Bot. 2000, 51, 329-337. [CrossRef] [PubMed]

60. Honma, T.; Goto, K. Complexes of MADS-box proteins are sufficient to convert leaves into floral organs. Nature 2001, 409, 525-529. [CrossRef]

61. Theissen, G. Development of floral organ identity, stories from the MADS house. Curr. Opin. Plant Biol. 2001, 4, 75-85. [CrossRef]

62. Kaufmann, K.; Wellmer, F.; Muino, J.M.; Ferrier, T.; Wuest, S.E.; Kumar, V.; Serrano-Mislata, A.; Madueno, F.; Krajewski, P.; Meyerowitz, E.M. Orchestration of floral initiation by APETALA1. Science 2010, 328, 85-89. [CrossRef] [PubMed]

63. Chloe, D.M.; Tengbo, H.; Vivian, F.I. The Arabidopsis Floral homeotic proteins APETALA3 and PISTILLATA negatively regulate the BANQUO genes implicated in light signaling. Plant Cell 2010, 22, 690-702.

64. Mandel, M.A.; Yanofsky, M.F. A gene triggering flower formation in Arabidopsis. Nature 1995, 377, 522-524. [CrossRef]

65. Kotoda, N.; Wada, M.; Kusaba, S.; Kano-Murakami, Y.; Masuda, T.; Soejima, J. Overexpression of MdMADS5, an APETALA1-like gene of apple, causes early flowering in transgenic Arabidopsis. Plant Sci. 2002, 162, 679-687. [CrossRef]

66. Chi, Y.; Huang, F.; Liu, H.; Yang, S.; Yu, D. An APETALA1-like gene of soybean regulates flowering time and specifies floral organs. J. Plant Physiol. 2011, 168, 2251-2259. [CrossRef]

67. Dennis, L.; Peacock, J. Genes Directing Flower Development in Arabidopsis. Plant Cell 2019, 31, 1192-1193. [CrossRef]

68. Yanofsky, M.F.; Ma, H.; Bowman, J.L.; Drews, G.N.; Feldmann, K.A.; Meyerowitz, E.M. The protein encoded by the Arabidopsis homeotic gene agamous resembles transcription factors. Nature 1990, 346, 35-39. [CrossRef]

69. Alvarez-Buylla, E.R.; Pelaz, S.; Liljegren, S.J.; Gold, S.E.; Burgeff, C.; Ditta, G.S.; Ribas de Pouplana, L.; Martínez-Castilla, L.; Yanofsky, M.F. An ancestral MADS-box gene duplication occurred before the divergence of plants and animals. Proc. Natl. Acad. Sci. USA 2000, 97, 5328-5333. [CrossRef]

70. Zhao, X.Y.; Cheng, Z.J.; Zhang, X.S. Overexpression of TaMADS1, a SEPALLATA-like gene in wheat, causes early flowering and the abnormal development of floral organs in Arabidopsis. Planta 2006, 223, 698-707. [CrossRef]

71. Pérez-Ruiz, R.V.; García-Ponce, B.; Marsch-Martínez, N.; Ugartechea-Chirino, Y.; Villajuana-Bonequi, M.; de Folter, S.; Azpeitia, E.; Dávila-Velderrain, J.; Cruz-Sánchez, D.; Garay-Arroyo, A. XAANTAL2 (AGL14) is an important component of the complex gene regulatory network that underlies Arabidopsis shoot apical meristem transitions. Mol. Plant 2015, 8, 796-813. [CrossRef] [PubMed]

72. Zhang, C.; Tanabe, K.; Tamura, F.; Matsumoto, K.; Yoshida, A. 13C-photosynthate accumulation in Japanese pear fruit during the period of rapid fruit growth is limited by the sink strength of fruit rather than by the transport capacity of the pedicel. J. Exp. Bot. 2005, 56, 2713-2719. [CrossRef] [PubMed]

73. Huber, S.C. Relation between photosynthetic starch formation and dry-weight partitioning between the shoot and root. Can. J. Bot. 1983, 61, 2709-2716. [CrossRef]

74. Smith, A.M.; Stitt, M. Coordination of carbon supply and plant growth. Plant Cell Environ. 2007, 30, 1126-1149. [CrossRef] [PubMed]

75. Stitt, M.; Lunn, J.; Usadel, B. Arabidopsis and primary photosynthetic metabolism-More than the icing on the cake. Plant J. 2010, 61, 1067-1091. [CrossRef] [PubMed]

76. Boex-Fontvieille, E.; Rustgi, S.; Reinbothe, S.; Reinbothe, C. A Kunitz-type protease inhibitor regulates programmed cell death during flower development in Arabidopsis thaliana. J. Exp. Bot. 2015, 66, 6119-6135. [CrossRef] 